GASTER Vol. XV No. 1Februari 2017

\title{
PENGETAHUAN DAN PENERAPAN FIVE MOMENTS CUCI TANGAN PERAWAT DI RSUD SUKOHARJO
}

\author{
Rlyani Wulandarl, Slti Shollkah \\ STIKES 'Alsylyah Surakarta \\ rlyanloute@yahoa.caid
}

\begin{abstract}
ABSTRAK
Pendahuluan; Pasien rawatinap di rumbahh salkitmengalami infeksi nosokomial sebesar 1,4 juta infeksi setiap tahunnya. Infeksi nosokomial dapat dicegah dengan 10\% lingkungan dan 90\% perilaku. Salah satu perilaku untuk mencegah terjadinya infeksi nosokomial adalah dengan melakukan cuci tangan. WHO (2009) merumuskan strategi pencegahan infeksi nosokomial dengan menerapkan five moments cuci tangan perawat. Tujuan; Mengetahui gambaran pengetahuan dan penerapan five moments cuci tangan perawat di RSUD Sukoharjo. Metode Penelitian ini adalah jenis penelitian Deskriptif dengan teknik total sampling dengan subyek penelitian adalah perawat ICU dan NICU sebanyak 29 responden. Instrumen penelitian ini menggunakan kuesioner dan lembar observasi. Analisa yang digunakan yaitu analisa univariat. Hasil; Hasil penelitian pengetahuan dengan hasil pengetahuan baik yaitu sebesar 22 responden (75,9\%) dan pengetahuan cukup dengan 7 responden (24,1\%). Sebagian besar perawat sudah menerapkan five moments cuci tangan yaitu 17 responden $(58,6 \%)$ dan perawat yang tidak menerapkan five moments cuci tangan yaitu 12 responden $(41,4 \%)$. Kesimpulan; Pengetahuan perawat tentang five moments cuci tangan adalah baik dan sebagian besar peraw at telah menerapkan five moments cuci tangan.
\end{abstract}

Kata Kundi : cuci tangan, five moment, pengetahuan, perawat

\begin{abstract}
Background, Inpatients in the hospital experiencing nosocomial infections at 1.4 million infections every year. Nosocomial infections can be prevented by condition of $10 \%$ and behavior $90 \%$. One of the behaviors for preventing the occurrence of nosocomial infections is by hand hygiene. WHO (2009) explain that a strategy of prevention of nosocomial infections with applying the five moments of hand washing by the murses. Purpose; know the description of knowledge and application of the five moments of hand hygiene murses at hospital Sukoharjo Method This research is descriptive research with total sampling technique in which the research respondents were 29 respondents of nurses ICU and NICU at hospital Sukoharjo. The research instruments using questionnaires and observation sheets. Analyzing of the data using univariate analysis. Result Results of research knowledge with good knowledge at 22 respondents (75.9\%) and insufficient knowledge with 7 respondents (24.1\%). Most nurses are already applying the five moments of hand hygiene is 17 respondents (58.6\%) and murses who do not implement the five moments of hand hygiene, which is 12 respondents (41.4\%). Condusion; Knowledge of nurses about five momens hand hygiene is good and most of the murses have applied five moments of hand hygiene.
\end{abstract}

Keywords: hand hygiene, five moments, knowledge, nurse

18 Pengetahuan dan Penerapan Five... 


\section{A. PENDAHULUAN}

Angka kejadian infeksi nosokomial terjadi pada beberapa negara maju. Pasien rawat inap di rumah sakit mengalami infeksi yang baru selama dirawat sebesar 1,4 juta infeksi setiap tahun. Suatu penelitian yang dil lakukan oleh WHO (World Health Organization) menunjukkan bahwa sekitar 8,7\% dari 55 rumah sakit di 14 negara yang berasal dari Eropa, Timur Tengah, Asia Tenggara dan Pasifik tetap menunjukkan terdapat infeksi nosokomial dengan Asia Tenggara sebanyak 10,0\%. Jumlah infeksi nosokomial di 10 RSU Indonesia pada tahun 2010 mencapai 6-16\% dengan ratarata 9,8\% sedangkan di wilayah Jawa Tengah infeksi nosokomial mencapai $0,5 \%$. Infeksi nosokomial dapat dicegah dengan $10 \%$ lingkungan dan $90 \%$ perilaku. Salah satu perilaku untuk mencegah penyebaran penyakit dari orang ke orang atau dari peralatan ke orang dapat dilakukan dengan meletakkan penghalang diantara mikroorganisme dan individu (pasien atau petugas kesehatan). Penghalang dapat berupa upaya fisik berupa cuci tangan (Abdullah ,2014).

Cuci tangan menjadi salah satu langkah yang efektif untuk memutuskan rantai transmisi infeksi, sehingga insidensi infeksi nosokomial dapat berkurang. Pencegahan melalui pengendalian infeksi nosokomial di rumah sakit ini mutlak harus dilaksanakan oleh seluruh jajaran managemen rumah sakit meliputi para dokter, bidan, perawat dan lainlain (Darmadi, 2008)

Pada tahun 2009, WHO mencetuskan global Patient Safety a World Alliance for

\section{GASTER Vol. XV No. 1Februari 2017}

Safer Health Caredengan Save Lives Clean You Hands, yaitu merumuskan inovasi strategi penerapan Hand Hygiene untuk petugas kesehatan dengan My five Moments for Hand Hygiene adalah melakukan cuci tangan:sebelum bersentuhan dengan pasien, sebelum melakukan prosedur bersih/steril, setelah bersentuhan dengan cairan tubuh pasien resiko tinggi, setelah bersentuhan dengan pasien, setelah bersentuhan dengan lingkungan sekitar pasien (WHO, 2009).

Penelitian yang dilakukan oleh Pateda dan Rabbani (2013) didapatkan hasil bahwa perilaku cuci tangan baik sebesar $16,7 \%$, perilaku cuci tangan kurang baik sebesar 24,4\% dan perilaku cuci tangan buruk dengan hasil paling banyak yaitu 59\%. Perilaku yang buruk terbentuk oleh 3 faktor, yaitu faktor predisposisi yang meliputi pengetahuan, sikap, kepercayaan, keyakinan dan nilainilai. Faktor pendukung berupa lingkungan fisik, fasilitas dan sarana kesehatan cuci tangan serta faktor pendorong yang terwujud dalam sikap dan perilaku petugas kesehatan (Rumapea dan Saragih, 2010).

Five moments cuci tangan pada perawat belum diterapkan dengan baik hal ini didukung oleh penelitian Koeswo dan Pratama (2015) dimana didapatkan hasil perawat tidak melakukan cuci tangan pada momen pertama sebesar $52 \%$, momen kedua $50 \%$, momen ketiga $75 \%$, momen kempat $69 \%$ dan momen kelima sebanyak $78 \%$.

Pengetahuan perawat tentang five moments cuci tangan sangat berpengaruh terhadap perilaku five moments cuci tangan dimana dalam penelitian Rabbani (2013) 


\section{GASTER Vol. XV No. 1 Februari 2017}

pengetahuan perawat tentang five moments cuci tangan masih dalam kategori kurang baik dengan hasil tingkat pengetahuan five moments cuci tangan masuk dalam kategori kurang baik dengan presentase $70,5 \%$.

Kasus infeksi nosokomial di RSUD Sukoharjo yaitu sebanyak 81 kasus selama satu tahun. RSUD Sukoharjo merupakan rumah sakit tipe $B$ yang sudah menerapkan kebijakan five moments cuci tangan untuk petugas kesehatan yang berada di wilayah rumah sakit khususnya pada ruang ICU dan NICU.Hasil wawancara dengan tim PPI rumah sakit, meskipun sudah ada kebijakan five moments cuci tangan masih ada perawat yang bel ummematuhi kebijakan tersebut, hal tersebut dikarenakan kurangnya pengetahuan perawat tentang five moments cuci tangan. Hasil wawancara dengan 15 perawat di ruang ICU dan NICU, 9 diantaranya tidak hafal urutan langkah cuci tangan dan five moments cuci tangan dan 6 lainnya mengatakan mengetahui langkah cuci tangan dan five moments dengan urut. Hasil observasi kepada 15 perawat, 11 diantaranya melakukan cuci tangan menggunakan air mengal ir dan sabun tetapi tidak menerapkan SOP (Standart Operasional Prosedur) yang berlaku, 3 diantaranya hanya menggosok telapak dan punggung tangan setelah itu membilasnya dengan air serta 1 diantaranya hanya menggosok telapak tangan, punggung tangan dan sela jari lalu membilasnya. Penerapan five moments dari 15 perawat, 13 diantaranya menerapkan cuci tangan pada momen setelah terpapar cairan tubuh pasien, setelah menyentuh pasien dan setelah menyentuh

20 Pengetahuan dan Penerapan Five ... sekitar pasien, 2 diantaranya melakukan five moments setelah menyentuh pasien dan setel ah menyentuh lingkungan pasien.

\section{B. BAHAN DAN METODE}

Jenis penelitian yang digunakan adalah penelitian deskriptif kuantitatif. Lokasi penelitian adalah di RSUD Sukoharjo. Populasi yang digunakan adalah perawat di ruang ICU dan NICU dengan jumlah 29 responden. Sampel yang digunakan yai tu total sampling dimana semua populasi diambil sebagai sampel sebanyak 29 responden. Instrumen yang digunakan yaitu lembar kuesioner dan observasi. Analisa penelitian yang digunakan yaitu anal isa univariat.

\section{HASIL DAN PEMBAHASAN}

Penelitian dilakukan untuk mengetahui gambaran pengetahuan dan penerapan five moments cuci tangan perawat di RSUD Sukoharjo dengan sampel sebanyak 29 perawat. Penelitian dilakukan pada bulan Mei-Juni 2016, dengan hasil penelitian sebagai berikut:

\section{Distribusi umur perawat}

Tabel 4.1

Distribusi Frekuensi K arakteristik

Responden Berdasarkan Umur

Perawat di bangsal IC U dan NICU

RSUD Sukoharjo

\begin{tabular}{cccc}
\hline No & Umur & Frekuensi & Presentase \\
\hline 1 & $21-30$ & 9 & 31,1 \\
2 & $31-40$ & 17 & 58,6 \\
3 & $41-50$ & 3 & 10,3 \\
\hline & Jumlah & 29 & 100 \\
\hline
\end{tabular}

Sumber : data primer diolah, 2016 
GASTER Vol. XV No. 1Februari 2017

Berdasarkan tabel 4.1 menunjukkan bahwa dari 29 responden yang ada di bangsal ICU dan NICU RSUD Sukoharjo mayoritas memiliki umur 31-40 tahun sebanyak 17 responden (58,6\%) dan pal ing sedi kit memiliki umur 41-50 tahun yaitu sebesar 3 responden (10,3\%).

2. Distribusi Pendidikan Responden

Tabel 4.2

Distribusi Frekuensi K arakteristik Responden Berdasarkan Pendidikan

Perawat di Bangsal ICU dan NICU RSUD Sukoharjo

\begin{tabular}{clcc}
\hline No & Pendidikan & Frekuensi & Presentase \\
\hline 1 & Ners & 4 & 13,8 \\
2 & Sarjana & 2 & 6,9 \\
3 & Diploma 3 & 23 & 79,3 \\
\hline & Jumlah & 29 & 100 \\
\hline
\end{tabular}

Sumber : data primer diolah, 2016

Berdasarkan tabel 4.2 menunjukkan bahwa dari 29 responden di bangsal ICU dan NICU RSUD Sukoharjo, mayoritas responden mempunyai pendidikan Diploma 3 keperawatan sebanyak 23 responden (79,3 \%) dan frekuensi pendidikan paling sedikit adalah sarjana sebanyak 2 responden (6,9\%).

3. Distribusi masa kerja perawat

Tabel 4.3

Distribusi Frekuensi K arakteristik

Responden Berdasarkan M asa

Kerja Perawat di Bangsal ICU dan

NICU RSUD Sukoharjo

\begin{tabular}{clcc}
\hline No & Masa Kerja & Frekuensi & Presentase \\
\hline 1 & $1-5$ tahun & 7 & 24,2 \\
2 & 6-10 tahun & 8 & 27,6 \\
3 & 11-15 tahun & 9 & 31,0 \\
\hline
\end{tabular}

\begin{tabular}{cccc}
\hline No & Masa Kerja & Frekuensi & Presentase \\
\hline 4 & $16-20$ tahun & 5 & 17,2 \\
\hline & Jumlah & 29 & 100 \\
\hline
\end{tabular}

Sumber : data primer diolah, 2016

Berdasarkan tabel 4.3 menunjukkan bahwa dari seluruh responden yang ada di bangsal NICU dan ICU RSUD Sukoharjo, mayoritas responden memiliki pengal aman masa kerja 11-15 tahun yaitu sebanyak 9 responden $(31,0 \%)$ dan pal ing sedikit masa kerja responden adalah 16-20 tahun sebanyak 5 responden $(17,2 \%)$.

4. Distribusi pengetahuan perawat tentang five moments cuci tangan

Tabel 4.4

Distribusi Frekuensi Pengetahuan

Perawat Tentang Five M oments $\mathrm{Cuci}$

Tangan di Bangsal ICU dan NICU

R SUD Sukoharjo

\begin{tabular}{clcc}
\hline No & Pengetahuan & Frekuensi & Presentase \\
\hline 1 & Baik & 22 & 75,9 \\
2 & Cukup & 7 & 24,1 \\
3 & Kurang & 0 & 0 \\
\hline & Jumlah & 29 & 100 \\
\hline
\end{tabular}

Sumber : data primer diolah, 2016

Hasil penelitian pada tabel 4.4 menunjukkan bahwa dari seluruh responden yang ada dibangsal NICU dan ICU RSUD Sukoharjo, mayoritas responden memiliki pengetahuan baik sebanyak 22 responden $(75,9 \%)$. Mendukunghal tersebutmenurutpenelitian Yulianti (2011) pengetahuan merupakan demen yang sangat penting untuk terbentuknya tindakan seseorang. Dimana didapakan hasil bahwa ada hubungan antara pengetahuan perawat dengan 


\section{GASTER Vol. XV No. 1 Februari 2017}

penerapan universal precaution pada perawat. Salah satu penerapan universal precaution pada perawat adalah dengan melakukan five moments cuci tangan. Seorang perawat dikatakan professional, jika memiliki pengetahuan keterampilan serta memiliki sikap professional sesuai kode etik profesi. Pengetahuan perawat dapat terus meningkat apabil a rumah sakit dapat terus meningkatkan kemampuan dengan berbagai pelatihan dan edukasi berkesinambungan bagi seluruh karyawan pada semua aspek pencegahan infeksi adalah dengan menerapkan five moments cuci tangan.

Menurut teori dari Saragih dan Rumapea(2012) upayauntukmeningkatkan pengetahuan dengan memberikan kesadaran melalui kegiatan yang disebut penyuluhan kesehatan. Sehingga dengan pengetahuannya akan meni mbulkan sikap dan akhimya menyebabkan individu atau kelompok akan berperilaku yang didasarkan pada kesadaran dan kemauan individu yang bersangkutan. Hal itu didukung oleh penelitian Jamaluddin (2012) dimana didapatkan peningkatan pengetahuan karena diadakannya sosialisasi penyuluhan cuci tangan untuk perawat, sebelum dilakukan sosialisasi hanya sekitar $80 \%$ dan setelah dilakukan sosialisasi meningkat menjadi 100\% pengetahuan perawat tentang pentingnya cuci tangan dan prosedur cuci tangan. Perilaku yang didasari oleh pengetahuan akan lebih langgeng daripada perilaku yang tidak didasari oleh pengetahuan.
Hal tersebut didukung oleh teori dari Listiowati dan Widyanita (2014) dimana faktor kurangnya pengetahuan akan mempengaruhi ketaatan petugas dalam melakukan praktek hand hygiene.

Pengetahuan perawat di bangsal ICU dan NICU tentang five moments cuci tangan sebagian besar baik dikarenakan perawat di RSUD Sukoharjo mendapatkan sosialisasi dari tim Panitia Pengendalian Infeksi (PPI) rumahsakit. Selain sosial isasi yang dilakukan, tim PPI rumah sakit juga mengingatkan pentingnya melakukan five moments cuci tangan dengan media poster yang terdapat di dinding ruangan dan leaflet yang dibagikan untuk seluruh jajaran petugas kesehatan di rumah sakit khusunya bangsal ICU dan NICU.

Pengetahuan perawat di RSUD Sukoharjosebagian besar baik, hal tersebut dipengaruhi ol eh beberapa faktor, dimana faktor yang mempengaruhi pengetahuan menurut Wawan dan Dewi (2011) adalah pendidikan, umur, pekerjaan, lingkungan dan sosial budaya. Pendidikan perawat di bangsal ICU dan NICU tergolong mempunyai pendidikan yang tinggi dimanaperawatmemiliki pendidikanakhir ners sebanyak 4 perawat, sarjanasebanyak 2 perawat dan diploma 3 keperawatan sebanyak 23 perawat Menurut teori Mubarak (2011) mengatakan bahwa tingkat pendidikan berarti bimbingan yang diberikan oleh seseorang terhadap perkembangan orang lain menuju ke arah suatu cita-cita tertentu. Pendidikan adalah salah satu usaha untuk mengembangkan 


\section{GASTER Vol. XV No. 1Februari 2017}

kepribadian dan kemampuan di dalam dan di luar sekolah dan berlangsung seumur hidup. Semakin tinggi pendidikan seseorang semakin mudah pula untuk menerima informasi, dan pada akhirnya makin banyak pula pengetahuan yang dimiliki oleh perawat tentang pencegahan infeksi nosokomial berupa five moments cuci tangan.

Selain pendidikan, faktor umur juga mempengaruhi pengetahuan perawat, dimana umur perawat di bangsal ICU dan NICU termasuk dalam usia yang matang yaitu mayoritas memiliki umur 31-40 tahun yaitu sebanyak 17 perawat, dimana tingkat kematangan dan kekuatan perawat akan lebi $\mathrm{h}$ matang dal am berpi kir dan bekeja yang akan mempengaruhi pengetahuan perawat tentang five moments cuci tangan. Semakin meningkat umur seseorang maka semakin banyak pengal aman yang didapat dan banyaknya ilmu pengetahuan yang diperoleh. $\mathrm{Hal}$ tersebut sesuai dengan penelitian Mathuridy (2015) yang menyatakan bahwa umur perawat berhubungan dengan banyaknya pengalaman yang diperoleh dalam hidup. Umur juga berkaitan dengan kemampuan fisik dalam melaksanakan tugas dan kewajibannya sebagai perawat. Dapat dikatakan semakin matang usia seseorang maka semakin dapat menentukan hal-hal yang dianggap baik dan tidak baik yang akan semakin memperbaiki dan meningkatkan keterampilan dan pengetahuan perawat tentang. five moments cuci tangan.
Faktor lain yang mempengaruhi pengetahuan adalah masa kerja, dimana hal tersebut sesuai dengan teori Riyanto dan Budiman (2013) pengalaman belajar dalam bekerja yang dikembangkan akan memberikan pengetahuan dan keterampilan professional, serta dapat mengembangkan kemampuan mengambil keputusan yang merupakan manifestasi dari keterpaduan menalar secara ilmiah. Perawat di bangsal ICU dan NICU sejumlah 9 perawat memiliki masa kerja yang cukuplamayaitu 11-15tahun, dimana hal tersebut mempengaruhi pengetahuan perawat tentang.five moments cuci tangan. Perawat yang sudah memiliki masa kerja cukup lamazkan lebih mengetahui tentang five moments cuci tangan dibandingkan dengan perawat yang baru saja masuk ke dunia kerja.

\section{Distribusi Penerapan Five Moments Cuci Tangan Perawat}

Tabel 4.5
Distribusi Frekuensi Penerapan Five Moments $\mathrm{C}$ uci Tangan Perawat di Bangsal ICU dan NICU RSUD Sukoharjo

\begin{tabular}{|c|c|c|c|}
\hline \multicolumn{3}{|c|}{ Penerapan } & \multirow[b]{2}{*}{ Presentase } \\
\hline No & $\begin{array}{l}\text { Five Moments } \\
\text { Cuci Tangan }\end{array}$ & Frekuensi & \\
\hline 1 & Menerapkan & 17 & 58,6 \\
\hline 2 & $\begin{array}{l}\text { Tidzk } \\
\text { menerapkan }\end{array}$ & 12 & 41,4 \\
\hline & Jumlah & 29 & 100 \\
\hline \multicolumn{4}{|c|}{ Sumber : data primer diolah, 2016} \\
\hline & $\begin{array}{l}\text { Hasil pene } \\
\text { perawat di }\end{array}$ & $\begin{array}{l}\text { menu } \\
\text { sal ICl }\end{array}$ & $\begin{array}{l}\text { kkan da } \\
\text { dan } \mathrm{NICl}\end{array}$ \\
\hline
\end{tabular}




\section{GASTER Vol. XV No. 1 Februari 2017}

RSUD Sukoharjo, 17 responden sudah menerapkan five moments cuci tangan dengan presentase $58,6 \%$. Five moments cuci tangan meliputi mencuci tangan sebelum bersentuhan dengan pasien, sebelum melakukan prosedur bersih/ steril, setelah bersentuhan dengan cairan tubuh pasien, mencuci tangan setelah bersentuhan dengan pasien dan mencuci tangan setelah bersentuhan dengan lingkungan pasien.

Hasil penelitian menunjukkan sebagian besar perawat sudah menerapkan five moments cuci tangan. Hasil ini didukung oleh Yulianti (2011) dimana didapatkan hasil observasi penerapan cuci tangan perawat di bangsal rawat inap RS PKU Muhammadiyah Yoyakarta tergol ong baik dengan presentase $79,41 \%$. Penerapan cuci tangan perawat yang baik didukung oleh kesadaran dari perawat itu sendiri dalam melindungi diri dan pasien dari bahan infeksius serta kesadaran dal am menjalankan SOP yang benar. Kebiasaan mencuci tangan perawat dirumah sakit, merupakan perilaku mendasar dalam upaya pencegahan cross infection (infeksi silang). Selain kesadaran dari perawat, pengetahuan juga mempengaruhi sikap perawat dalam mencuci tangan.

Hal ini didukung oleh penelitian Hikmayanti (2015) pengetahuan perawat akan mendasari perawat tersebut untuk patuh dan menyadari betul bahwa mencuci tangan lima moment merupakan hal yang penting untuk pencegahan penularan infeksi, sehingga pada saat melakukan asuhankeperawatankepadapasien perawat akan patuh mencuci tangan lima moment untuk keselamatan diri perawat itu sendiri. Banyak hal yang mempengaruhi perilaku cuci tangan yang baik, diantaranya status petugas kesehatan yaitu non dokter, dan juga pengenalan penggunaaan handrub berbasis alkohol. Sedangkan untuk perilaku cuci tangan yang buruk dapat dipengaruhi oleh kurangnya fasilitas cuci tangan yang bai k seperti wastafel, kran air, sabun cuci tangan dan handuk atau tisu kering.

Perawat belum sepenuhnya melakukan five moments cuci tangan dikarenakan beberapa faktor, dimana hasil wawancara dengan perawat didapatkan faktor yang menyebabkan ketidakpatuhan dal am melaksanakan hand hygiene adalah aktivitas yang terlalu sibuk, pasien yang banyak, mementingkan pasien terlebih dahulu, panduan dan pengetahuan hand hygiene yang tidak memadai, hand hygiene dapat mengganggu hubungan baik dengan pasien, memiliki anggapan resiko rendah untuk mendapatkan infeksi dari pasien, lupa untuk mencuci tangan. Faktor kurangnya pengetahuan juga ikut mempengaruhi ketaatan petugas dalam melakukan hand hygiene.

Selain faktor diatas menunt Jamaluddin (2012) secara umum alasan kurangnya kesadaran mencuci tangan adalah tingginya mobilitas perawat dan dokter sehingga secara praktis lebih mudah menggunakan sarung tangan, hal tersebut memicu tingginya penggunaan 


\section{GASTER Vol. XV No. 1Februari 2017}

sarung tangan yang didukung kelalaian untuk cuci tangan sebelum dan setelah menggunakannya.

Dari pembahasan diatas dapat disimpulkan banyaknya faktor yang menyebabkan penerapan cuci tangan perawat di bangsal ICU dan NICU. Penerapan cuci tangan yang baik di ICU dan NICU RSUD Sukoharjo dikarenakan fasilitas mencuci tangan yang sudah lengkap, mudah dijangkau oleh perawat, pengetahuan perawat yang baik dan kesadaran dari dalam diri perawat tersebut. Pengetahuan perawat yang baik akan memicu perawat untuk lebih patuh melakukan cuci tangan. Selain itu, masa kerja perawat juga ikut mempengaruhi perilaku dari seseorang. Dimana didapatkan hasil bahwa sebagian besar perawat memiliki pengalaman masa kerja 11-15 tahun. Hal ini sesuai dengan teori Rivai dan Mulyadi (2010) masa kerja dapat mempengaruhi pengalaman kerja seseorang, sehingga semakin lama bekerja diharapkan seseorang memiliki pengal aman kerja semakin banyak. Masa kerja yang lebih lama menunjukkan pengalaman kerja yang lebih pada seseorang dibandingkan dengan rekan kerja yang lain. Jadi dapat disimpulkan bahwa semakin lama seseorang bekerja maka semakin menguasai ketrampilan yang di lakukannya secara berulang setiap harinya dan menjadi kan suatu kebiasaan, seperti hal nya mencuci tangan dal am lima moment, perawat yang sudah lama bekerja dan menjadi kan cuci tangan sebagai suatu hal yang sangat penting maka perawat tersebut akan terbiasa melakukan cuci tangan dalam lima moment setiap harinya.

Faktorpendi dikanjugamempengaruhi perilaku seseorang dimana sebagian besar perawat di RSUD Sukoharjo mayoritas memiliki pendidikan akhir diploma 3, dimana menurut penelitian dari Puspasari (2015) perawat dengan tingkat pendi dikan D3, selama proses pendidikannya lebih banyak mendapatkan materi dan pengal aman praktek di rumah sakit apabila dibandingkan dengan perawat pada tingkat pendidikan S1 atau SPK, selain itu perawat D3 lebih banyak melakukan tindakan keperawatan sehingga perawat D3 lebih sering untuk berinteraksi dengan pasien, yang mana ketika melakukan interaksi dengan pasien, seorang perawat diharuskan selalu melakukan upaya perlindungan diri, yaitu dengan cara melaksanakan praktik dalam pencegahan infeksi nosokomial.

\section{SIMPULAN DAN SARAN}

\section{SIMPULAN}

Berdasarkan hasil analisis dan pembahasan pada bab sebelumnya, maka peneliti dapat memberikan kesimpulan sebagai berikut:

a. Tingkat pengetahuan five moments cuci tangan perawat di RSUD Sukoharjo mayoritas memiliki pengetahuan baik.

b. Penerapan five moments cuci tangan perawat di RSUD Sukoharjo, sebagian besar sudah menerapkan five moments cuci tangan.

Pengetahuan dan Penerapan Five... 


\section{GASTER Vol. XV No. 1Februari 2017}

\section{SARAN}

\section{a. Bagi Perawat}

Dengan hasil penelitian yang telah diperoleh, diharapkan perawat tetap memperbarui pengetahuan tentang five moments cuci tangan dan selalu membiasakan diri untuk menerapkan five moments cuci tangan dalam pencegahan infeksi nosokomial. b. Bagi Tim PPI Rumah Sakit

Diharapkan pemberian informasi tentang five moments cuci tangan dapat dilakukan secara rutin kepada semua jajaran rumah sakit, khususnya perawat yang bekerja di ruang ICU dan NICU.

\section{DAFTAR PUSTAKA}

Abdullah. 2014. Kebutuhan Dasar Manusia untuk Mahasiswa Keperawatan. Jakarta: Trans Info Media.

Darmadi, S.M. 2012. Kepatuhan Hand Hygiene di Rumah Sakit Immanuel Bandung. J urnal Keperawatan Universitas Padjajaran Bandung Vol 8. No 1. Maret 2012

Hikmayanti,K. 2015. Faktor-Faktor Yang Berhubungan Dengan Kepatuhan Perawat Dalam Mencuci Tangan 5 Moment di Ruang Perawatan Crysanthenum dan Orchid Siloam Hospitals Cikarang Tahun 2015. J urnal IImiah Keperawatan STIKes Medika Cikarang Vol 5. No 1. Mei 2015.

Jamal uddin. 2012. Kepatuhan Cuci Tangan 5 Momen di Unit Perawatan Intensif. J urnal Kedokteran Terapi Intensif Vol 2. No 3. Juli 2013.

Koeswo,M dan Pratama,B. 2015. Faktor Determinan Kepatuhan Pelaksanaan Hand Hygiene pada Perawat IGD RSUD dr. Iskak Tulungagung. J urnal Kedokteran Brawijaya Vol 28. No 2.

Listiowati,E danWidyanita,A. 2014. Hubungan Pengetahuan Hand HygieneDengan Kepatuhan Pelaksanaan Hand Hygiene Pada Peserta Program Pendidikan Profesi Dokter. J urnal Biomedika Vol 6. No.1. Februari 2014.

Mathuridy,R. 2015. Hubungan Umur, LamaKerja, Pendidikan dan Motivasi dengan Kepatuhan Perawat Melakukan Enam Langkah Lima Moment Cuci Tangan di Ruang ICU RSUD Ulin Banjarmasin. J urnal Penelitian Sekolah Tinggi IImu Kesehatan Muhammadiyah Banjarmasin Vol 3. No 2. September 2015.

Mubarak,I. 2011. Promosi Kesehatan: Sebuah Pengantar Proses Belajar Mengajar Dalam Pendidikan. Jakarta: Graha IImu

Pateda,V dan Rabbani,I. 2013. Hubungan Pengetahuan Terhadap Perilaku Cuci Tangan Petugas Kesehatan di Bagian IImu Kesehatan Anak BLU RSUP Prof Dr RD Kandou Manado. Jurnal Kedokteran Universitas Sam Ratulangi Manado Vol 3.No 5. Oktober 2013. 
Riyanto,A dan Budiman. 2013. Kapita Selekta Kuesioner Pengetahuan dan Sikap dalam Penelitian Kesehatan. J akarta: Sal emba Medika.

Rivai,V dan Mulyadi. 2010. Kepemimpinan dan Perilaku Organisasi. Edisi Ketiga. J akarta: Raja Grafindo Persada.

Saragih,R dan Rumapea,N. 2010. Hubungan Karakteristik Perawat Dengan TingkatK Kepatuhan Perawat Melakukan Cuci Tangan di Rumah Sakit Columbia Asia Medan. Publikasi Ilmiah Fakultas Ilmu Keperawatan Universitas Darma Agung Medan.

WHO. 2009. World Alliance for Patient Safety Global Patient Safety Challenge: 2005-2006. Switzerland: WHO Document Production Servies.

Yulianti. 2011. Hubungan Tingkat Pengetahuan Perawat dengan Penerapan Universal Precaution Pada Perawat di Bangsal Rawat I nap Rumah Sakit PKU Muhammadiyah Yogyakarta. J urnal Kesehatan Masyarakat Vol5. No 2. Juni 2011. 